\title{
The Politics of Policy Practices
}

Natalie Gill, Vicky Singleton and Claire Waterton

\section{Abstract}

This collection explores the relations between policy and care drawing on two specific sources of inspiration - that of Science and Technology Studies (STS) and that of Critical Policy Studies. It takes as its starting point a tension within and between the anticipated features of policy and those of care. Policy is often expected to provide general statements, protocols and directives, measurable outcomes, targets and indicators in order to guide and control. But policy - no less than care - is also a set of open-ended practices; policy is performed and re-performed in particular sites and settings and by particular actors, and so it is also a specific kind of ongoing and distributed 'doing'. It is not simply a generalised dictate. Characteristics of care, similarly, hold opposing dynamics in play. As well as configuring care as responsive, hesitant, situated and experimental practice (Mol et al 2010: 14), recent feminist research in STS has opened up questions about the non-innocence of care (Martin et al., 2015). Care has been enacted within particular histories where inequities of race, gender and power have often been to the fore. So, according to STS, both care and policy are practices: these practices mix humans and non-humans, and they are intimate with and implicated in technoscience. Policy, for example, has been examined as a technology (Harrison and Mort, 1998; Easthope and Mort, 2014) and care as technogovernance (May et al., 2006). As such, both policy and care distribute relations of power and generate categories of difference.

This collection has been put together at a time of seeming crisis in both policy and care. Care, including an alleged loss of care in public services, has become a focus of increased public concern, political debate and academic research in the UK, Europe and US. Moreover, many policies have been exposed as ineffective, harmful or deliberately weak. Hence it seems that there is currently a crisis in care that is bound up with a realisation that 'policies' are not care-full enough and may promote relations of neglect and suffering. This volume 
draws inevitably from this context, offering a collection of case studies of locations, relations and heterogeneous entities that make up policy practices in various sites. The contributions explore the different ways in which policy and care are entangled in these sites and at this time. The aim of the collection is to attend to, and engage in, the politics of policy practices and, ultimately, to explore how policy is and could be care. 


\section{Introduction}

The aim of this monograph is to open out what we see as the intimately entangled relations between policy and care. This introduction to the volume as a whole explores, in both theoretical and empirical detail, how these two terms and the practices to which they refer, do indeed relate. We need, however, to note at this early stage, that we are writing this Introduction within a specific context in which both care and policy seem beleaguered, in poor relation with one another, and under threat. Care has recently become a focus of increased public concern, political debate and academic research in the UK, Europe and US. News media, popular press, activist groups, political reports and statements by professional and public organisations have lamented a loss of care in public services. Moreover, many policies have been exposed as ineffective or harmful. There seems, currently, to be a crisis in care that is bound up with widespread public, professional and political realisation that in an increasing number of areas of contemporary society, policies are not care-full enough and may promote relations of neglect and suffering. For example, a series of reviews of health and social care in England have described unnecessary suffering, higher than expected mortality rates, neglect and abuse, and poor quality care on a systematic scale (Department of Health, 2013; Hudson, 2016) . Health and social care policy in England has been seen to be failing, if not causing harm to, those for whom it is supposed to care.

Policies do, of course, change over time and in relation to broad cultural and political shifts. Many contemporary policies are formed in the context of 'new public management', they bridge state and private sector actors, they often work across networks that span the globe, and they occupy new and increasingly commodified policy spaces (Ball and Junemann, 2012; Lingard and Sellar, 2013). The latter argue that policy work is no longer simply the work of governments. Rather, policy is "net-worked in a range of public and private, formal and informal processes, in which the influence on policy of large data sets, international comparisons and concerns for national productivity must be thought of in connection with the role of informal conversations, trust, and philanthropic generosities" (Lingard and Seller 2013 p 276). Within specific policy discourses and practices (e.g. education), an intensification of calculative rationalities is coupled with new affective intensities (Lingard 
and Seller 2013, p276). Policies are nowadays formulated with a 'mix of care and calculation' (Ball and Junemann 2012; see also Singleton and Mee, this volume).

This networked and multi-scale complexity of policy complicates long-standing issues of interest in policy making: questions of evidence, authority, universality, power, accountability, human and material diversity, local specificity and equity are now entangled in new global, semi-commodified spaces and rubrics. Yet nationwide policies still come into being through these networks and some of these - in planning and environmental protection in the UK for example - are currently concerned with devolving responsibility to spatially specific 'local' sites. Here again the dynamics are complex - whilst a local focus is seen to increase citizen agency, there are also cries that the traditional responsibilities of the State are being subtly evaded.

Up until the advent of 'Brexit' and the instatement of Donald Trump as US president, a pervasive shaping factor in policy making across the globe was that of neoliberalism. Major concerns within this context, which still persist in the UK and under the new American administration, have been that a rhetoric of crisis coupled with the politics of austerity in areas such as health care, social care, migration and the environment has facilitated the acceptance of policies that would otherwise be rejected (e.g. Tyler, 2013). Critics have argued that unacknowledged shifts in notions of responsibility had taken place under political regimes of neoliberalism and austerity which directly impact upon individuals through specific policies. The concern is that many public policies are marginalising and blaming, rather than protecting and including, those members of society who are most vulnerable, such as those living in poverty, those living and working in risky environments, those experiencing unemployment or living with mental and physical disability. At the very least these criticisms betray a lack of confidence in public policy to care for those for whom it is supposed to care. But these critiques, and the concerns that inform them, are now massively amplified in the context of Brexit and under the administration of President Trump. There is huge uncertainty about the future of regulation and policy in both the UK and the USA. The context has shifted and notions of 'care', let alone ideas of appropriate policies - for example concerning vulnerable populations of migrants in both nation states are in political turmoil. 


\section{The approach of the collection}

In relation to these and other causes of concern, in diverse domains, what 'care-full' policy might mean remains unformulated and under threat raising important questions, many of which are explored in this volume. For example, Gill explores how national UK policies for the recycling of domestic waste distribute responsibility for care. Clark and Bettini investigate how global policies for the abatement or mitigation of climate change intersect with concepts of planetary, human and non-human care. Tironi and Rodriguez-Girault document how activist groups in Chile make visible, and in some ways stand in for, a lack of care-full policy around copper smelting plants promising 'wealth and jobs' for local workers. And Gabrys explores the way that citizen DIY air pollution monitoring around fracking sites must turn to speculative practices to document harms that are accumulating and not fully known.

Drawing on a diversity of perspectives then, the authors within this collection are all concerned not to idealise 'care' but rather to trace its presence, its contours and its affects within specified policy domains. The collection is based around the conviction that there is a need for detailed empirical knowledge about how the relationship between care and policy is shaped in locations of practice. At the same time, there is an interest in 'good care' threading through the papers presented here. In particular the chapters, read together, emphasize attending, flexibility, specificity, responsiveness, experimentation and critically respectful engagement. Ideas of good care, despite being (or perhaps precisely because it is) variably constituted and context dependent, might support the making and maintenance of policy that is sensitive to the materialities and socio-economic specificities of locations of practice (Puig de la Bellacasa, 2011).

As suggested above and explored in more detail below, the collection brings together current research in Science and Technology Studies and theorising in Critical Policy Studies that often, but not exclusively, adopts ethnographic method and a material-semiotic approach. All of the papers focus on things and people in their relations and demonstrate that both policy and care are sets of heterogeneous practices done in material and variable ways in multiple locations. Notions such as policy as assemblage, policy as translation, and care as responsive tinkering and as experimental work, signal the fluidities and displacements of policy and care that the collection seeks to explore (Freeman, 2009; Freeman and Sturdy 2014; Lendvai and Stubbs, 2009; Mol, 2008; Schillmeier, 2014; 
Singleton, 2012). Policy and care are understood as complex, variable, decentred, and dependent on specific sets of relations, materialities and histories.

The collection addresses the problem that while policy can be seen as a specific form of care, the relationship between policy and care is complex and tense. We approach this conundrum through a series of case studies that interrogate the relationship between policy and care and open up what policy and care mean in specific locations. Frequently the anticipated features of policy and those of care are seen to work against one another. Policy is often expected to provide general statements, protocols and directives, measurable outcomes, targets and indicators in order to control practices, and problems with policy are understood as ineffective implementation. However, as work in Critical Policy Studies has shown policy is always translation and is enacted fluidly in specific locations of practice. Similarly, care is often seen as acts of nurturing that come from below and can be guided by policy: an influential body of recent work in Science and Technology Studies (STS) configures care as 'persistent tinkering in a world full of complex ambivalence and shifting tensions' (Mol et al., 2010; 14). Care is described as responsive, hesitant, emergent, experimental work (Schillmeier, 2014), but Feminist Technoscience scholars have also called for a critical engagement with care to explore its 'dark side' (Martin et al., 2015). Clearly policy and care are dense and suggestive terms and we open out each concept in turn below.

\section{Policy}

Many analysts of specific policies as well as 'policy analysts' have argued that policy is a product of, and often re-performs, the social, economic and political context in which it is produced (Clarke and Newman, 2009; Mosse,2005; Spandler and Stickley, 2011; Law and Singleton, 2014; Waterton, 2002). Consequently, definitions of policy and the processes of implementation have become increasingly complex and non-linear and yet traditional linear definitions of policy as a form of universal knowledge are common and often endorsed. The Cambridge English dictionary, for example, defines policy as 'a set of ideas or a plan of what to do in particular situations that has been agreed to officially by a group of people, a business organization, a government, or a political party', (accessed 4.7.16). If we want to capture a wider common definition of policy, a Google search retrieves numerous options that all suggest policy as a form of top-down knowledge and principles to guide situated action. 
Below we chart out theoretical engagements with policy that we consider are especially relevant to the approach of this collection. On the one hand, we trace studies of policy as having developed from a concern with implementation. In such studies policy itself is not scrutinised and tends to remain relatively intact. On the other hand, we look to a critical engagement with, and exploration of, the concept and characteristics of policy itself. Historically, policy studies have focused on how to ensure a better fit between policy (as a durable and fixed text) and local practices. More recently Critical Policy Studies have challenged the assumption that policy is ever immutable. Indeed, this work shows that implementation is not a problem to be solved but rather an on-going process to be understood.

In order to account for what policy means in this collection we here draw upon a diverse set of resources that suggest how hard it is to pin down what policy is. For example, in the much cited text Policy Analysis for the Real World, Hogwood and Gunn (1984) state that policy is subjectively defined and they describe policy as any or all of the following: a field of activity (e.g. foreign or health policy), a general intent (e.g. a drive to make the world a healthier place), a specific proposal (usually target driven), something that requires formal authorisation or legislation, implementing a programme of action. Hill and Varone (2004) in The Public Policy Process capture the academic consensus that it is notoriously difficult to define what policy is and note that most early work was focused on questions about transfer and behaviour change. This work critiqued the prevalent idea of a gap or 'missing link' between policy making and policy outcomes (e.g. see Hargrove, 1975). Indeed, much work has debated the very possibility of distinguishing between policy and implementation (Pressman and Wildavsky, 1984). Studies have explored the so called 'implementation gap' between policy aspirations and reality and reconceptualised policy transfer as an interactive and negotiated process requiring flexible, adaptive strategies (Matland, 1995; Pressman and Wildavsky, 1984). In this work policy has been figured as a cycle and implementation as a process that is a contextualised 'multidisciplinary, multi-level and multi-focus exercise looking at a multiplicity of actors, loci and layers' (Hill and Hupe, 2002, p 16). 
Detailed, ethnographic, policy-specific studies have characterised contemporary policies as, in themselves, increasingly multifaceted, complex and composed of thick interconnecting relations and heterogeneous actors. The practices and processes of policies assemble sets of heterogeneous actors including humans and an array of technologies such as templates, checklists and guidelines (Easthope and Mort, 2014). Easthope and Mort (2014) point to the many assumptions carried by such technologies, and Harrison and Mort (1998) figure policies as 'technologies of legitimation' which act to distribute relations of power and generate categories of difference (see also Caldwell, 1968; Jasanoff, 2006; Scott, 1998; Waterton and Wynne, 1996; Wynne 2001; Wynne 2002).

The idea of 'policy transfer' has also been further opened out in recent scholarship both within and outside Critical Policy Studies. Many authors understand transfer of policy to be a misnomer and that policy rests on in-situ meaning-making practices that are themselves uncertain, ordered in particular ways, prone to contingency, and sometimes messy (Clarke, 2012; Mosse, 2005; Waterton, 2002; Singleton and Law, 2014). Hence, to labour the point, 'policy' is not a singular translatable concept nor object and the contributions to this monograph demonstrate the multiple ways in which policy is figured. Use of the term 'policy' frequently suggests a generalised programme with claims to universal knowledge (signalled by vocabulary such as plan, strategy, proposed action, blueprint, approach, scheme, stratagem, programme, schedule, code, system, guidelines and/or intentions). However, the approach of the collection is to conceptualise policy as distributed practice across heterogeneous actors, relations and spaces. Hence, there is no way to distinguish policy from its implementation; policy is practice and is thereby multiple, specific, situated configurations of relations and actors.

Given this figuration of policy, the contributions of this collection pay particular attention to policy as both performance (policy as continually being done rather than existing outside of practice) and as performative (through doing policy various categories and identities are brought into being). ${ }^{1}$. The contributions attend to how policies-in-practices build particular worlds which are open-ended, subtly evolving assemblages of the social, material and conceptual. Policies in practice enact specific subjects and particular objects as important and powerful and others as marginal or excluded (Latour, 2004; Moser, 2008; Haraway, 
1991, 2007; Welsh and Wynne 2013). But policies and the practices that go with them are also incomplete: they change in relation to the wider assemblages of which they are part. The authors in this collection explore the distributions, simplifications and categorisations being produced in specific policy sites and suggest, or enact, ways in which distributions could be otherwise.

This collection reflects, contributes to and interrogates various policy practices within different kinds of contemporary networks. Some of the case studies are shaped by what we have characterised as a more generalised context of crisis, critique and scepticism surrounding policy. None of the papers look specifically at the making of policy. However, the collection asks through empirical examples of many different situations, how policy and care might be reconfigured together. And so, before we turn to the specific policy domains that feature in this collection - including those of human health, domestic and industrial waste management, fisheries, biodiversity, air pollution, climate change, migration, disease management and food standards - we look in more detail at some of the recent research on care. In particular we focus on work in Science and Technology Studies that figures care as responsive tinkering and as experimental and situated practices, but also as a practice that has often been connected to inequitable sociotechnical relations. The collection explores this STS work, which often follows policy enactments to sites well-removed from the policymaker's domain, together with work of Critical Policy Studies - an area of research that has focussed much more extensively on the actual crafting of policy within particular institutional and governance settings. All authors, in their specific policy domains and settings, explore how new figurations of care are generative of conditions of possibility for more care-full policy practices.

\section{Care}

Research exploring the variable constitution of care has proliferated in the last decade, and this research has a diverse theoretical as well as empirical provenance. We cannot adequately capture the breadth and richness of this literature here ${ }^{1}$. Hence we offer a review of specific literatures that relate to the contributions to this collection which is concerned with how practices of care and policy-in-practices are entangled, held apart, interfere with or support one another and how they shape the realities that citizens and publics come to live with. ${ }^{2}$ 
Recently there has been a growth of work in Science and Technology Studies about care. This work includes studies of care in practice that revision and revalue mundane practices of tinkering and experimentation as characteristic of good care (Mol et al. 2010; Mol, 2008; Pols, 2006, 2012). Similarly, scholars in feminist technoscience studies are currently developing an approach termed Critical Care. This approach interrogates both the harmful and nurturing aspects of care. Moreover it reclaims care as a mode of response-able critical and constructive engagement with the technoscientific worlds that we study, are implicated in and produce. This reflects Puig de la Bellacasa's (2011) exploration of the character of constructive critique in which she urges scholars to attend to 'matters of care' in technoscience. ${ }^{3}$ Her work suggests that scholars should study things that they care about, both substantively and also as a political project.

Many of the studies of care-in-practice suggest that it is difficult to know what 'good care' is outside the practices in which it is produced (Mol et al., 2010; Mol, 2008; Pols, 2006, 2012). This body of work, much of which comes from ethnographic studies of health care, conceptualises good care as emergent and collaborative practices of relating, the effect of on-going tinkering that attunes knowledges, bodies, technologies and lives. Care is hence reconceptualised as not a purely human endeavour but rather as mixing heterogeneous entities and as technological through and through, even as technogovernance (Pols, 2012; May et al., 2006). Hence what is deemed to be care is specific, located and produced in mundane practices. Crucially, Schillmeier (2014) attends to caring relations as experimental, flexible, context-specific work that is at odds with neo-liberal economies of care and the policies produced within this milieu (see also Latimer, 2000). To offer a specific example, detailed work on practices of care in ageing has drawn attention to the limitations of institutionalized care and the futility of the search for a technological fix to concerns about inadequate care provision for an ageing population (Milligan et al., 2011). We might add that this sense of futility itself, however, requires care-full thought, especially in relation to current political ideologies that bear on the responsibilities of 'the community' rather than the State.

An important and on-going context for the above work is the long tradition of work on feminist ethics of care that has exposed the politics inherent in caring relations and in 
definitions of care (Gilligan, 1982; Sevenhuijsen, 2003; Tronto, 1993, 2005) . In particular, a feminist ethics of care has attuned us to how care work is often hidden, for example domestic care work, and that invisibility has obscured inequities in distributions of who does the caring, and who and what is deemed worthy of being cared for. Scholars have noted that historically care is seen to come from below and have sought to disrupt and to rearrange traditional arrangements of care (Martin et al., 2015). Many of the contributions to this volume are doing this work of disruption and rearrangement.

Just as the relations of 'policy' have come to display more complex public-private, formalinformal, commodified and spatially sprawling qualities, so too have the characteristics and practices of 'care' shifted and been re-situated in recent years. Care work, in many domains, has become appropriated by markets, and has been subject to the divisions, stratifications, classifications, articulations and temporalities of liberal economic relations (Leem, 2015; Puig de la Bellacasa, 2015; Schillmeier and Domènech, 2010; see also Lavau and Bingham this volume). Since the Western financial crash of 2008 , in particular, care governed through the public sector has been subject to punishing austerity measures and to audits (sometimes of care itself, see Singleton and Mee, this volume) that alienate those caring as well as those cared for. In more ambiguous, extreme and sometimes international situations the human impulse to care has come under intense pressure - for example in situations of war, disaster and immigration (Ticktin, 2011; Convery et al., 2008 ; Easthope and Mort, 2014; Clark and Bettini, this volume). Relations and practices or 'doings' of care (Puig de la Bellacasa, 2011; Mol, 2002; Barad, 2007) within such difficult and traumatised situations have at times become distorted, almost unrecognisable as care. As we have rehearsed above, these pressures seem to be intensifying further under Brexit and the administration of President Trump (see Lavau and Bingham this volume for a discussion of this in relation to food safety).

Thinking about care, with care, as Martin et al., (2015) suggest, therefore 'requires attention to the ambivalent rhetorics and practices taken up in its name' $(2015, \mathrm{p} 630)$. This work asserts that 'the politics of knowledge cannot be disarticulated from a politics of care' (Martin et al., 2015, p 630). So, Puig de la Bellacasa's (2011) call for scholars attend to 'matters of care' in technoscience through affectively charged analytical engagement is, she claims, likely to be especially attentive to neglected and marginalised human and non- 
human entities (see Joks and Law, this volume; Tironi and Rodriquez-Giralt, this volume; Singleton and Mee, this volume).

Thinking about care, with care, may also require consideration of how this thing, care, comes about. Leem has recently written about anxiety as a productive source of care practices, reminding us that care need not necessarily be motivated by positive feelings of nurture. Care can equally be inspired by injury, injustice, indignation or frustration - or situations which indicate a lack of care (Martin et al., 2015, p 630; Murphy, 2015). Care begins, she suggests, when we 'listen to, respond to or learn our shared anxieties' (Leem 2015, p 48). This seems especially relevant in the light of the global political context outlined above, which is producing many specific and distributed anxieties. Leem suggests, however, that the sharing of anxieties is 'only a beginning of caring' (2015, p 48). An additional concern is the fraught question of how to care (Schrader 2015; Viseu 2015; Atkinson-Graham et al., 2015) and how issues of affect, responsibility and shared relations work to produce care. Many analysts seem currently to be arguing for an attuned sensibility to affect, and for a honed ability to look and listen, but also to respond as essential to care practices (Barad 2007; Haraway 2008; Schrader 2012; Martin et al., 2015).

At the same time 'critical care studies' pay specific attention to the problematic social stratifications of care work. Such studies suggest that practices of care are often not only undervalued and unarticulated but are also often left interrogated, or unquestioned. Through this work scholars examine the 'dark side of care' - the classed, racialized and gendered ways in which care has been 'feminised, devalued, overlooked, or rendered invisible by materially and morally privileging mind over body, public over private, reason over emotion, and waged labor over unpaid care work' (Martin et al., 2015, p 628). Dwelling on such issues Murphy has called for an unsettling and vexation of the seeming innocence of care (Murphy, 2015). This commitment to unsettling of care as a taken for granted good can be clearly seen in the interrogations of care and policy practices in this volume.

\section{Emerging themes}


Framed by the above concerns and commitments, the contributions to this collection emerge from very different policy specific sites and situations and approach policy as multiple and variably constituted. This research could itself be seen as 'care work' - the authors have made efforts to research through the specificities and the enactments of particular policies in particular places. This has given rise to a number of emerging themes under which the chapters are organised.

\section{How policy cares for some things and neglects others}

One of the central themes that emerge in this collection is how, in practices of doing, different policies look after some things and neglect other things. Common characteristics identified with policy, such as scheduling of time and translocation of a protocol, often neglect the variability in, for example, material specificities of location. Moreover, things that are frequently neglected are those things in most need of care. For example, tacit skills that are essential to the doing of policy but are not articulated as such; precarious and temporary relations specific to particular caring situations; marginalised actors who lack resources for inclusion and visibility; and informal practices and negotiations that adapt and adjust protocols so that they fit specific locations. This attention to neglected things allows us to see that policies designed to protect and to nurture can often be perverse, inadvertently harbouring and promoting relations of harm. Policies aiming to promote choice may, at the same time, transfer responsibility and deny accountability of institutions. Policies promoting equality and citizenship may also promote specific aspirations and normativities such as active participation and in turn exclude alternative subjectivities. Moreover, policies designed to protect those in most need of care may resort to overly protective measures of sensitivity or control that deny individual needs and differences.

All of the authors in this collection are grappling with questions about how to include the marginalised, how to make visible that which is hidden or erased, how to strengthen that which is uncodified or uncommodifiable. All authors are paying attention to care sensibilities that are hard to capture, or eroded through policy protocols. The chapters clustered under this heading, 'how policy cares for some things and neglects others' are those by Stephanie Lavau and Nick Bingham, Nigel Clark and Giovanni Bettini and Michael Schillmeier. These authors explicitly make visible how care happens in unexpected places and unanticipated ways. In doing so they challenge the inevitability of existing arrangements and 
they add 'new' realities to expand the possibilities for more inclusive, less divisive, and more impure, heterogeneous relations of care.

Lavau and Bingham story how care and attention come together, and are teased apart, in practices of food safety inspection in the UK. They present food safety inspection not simply as a visual culture of surveillance, but as sensory, bodily attention to the objects, techniques and sites of animal and food production. It is through these practices of attention that food businesses are cared for. Their work examines the introduction of vulnerabilities regarding matters of attention brought about through recent regulatory changes which tend towards increased audit- and records-based care. Whilst food inspectors have long agreed that 'understanding the complexities of supply chains is much more than maintaining a paper trail' they urge for greater policy and regulatory appreciation of the situational and educational practices which cultivate a care of attention within this industry.

Lavau and Bingham's contribution suggests that those looking for policy-care practices need to be open to the observation of less likely places and practices to find nuanced modes of attention. Attention does not equal care but may be productive of it.. It is not the reregulation of new food inspection routines that will afford improved food safety care for smaller businesses like the ones that Lavau and Bingham have observed. Rather, it is the unacknowledged and ongoing practices of attention to demonstration that have allowed inspectors to teach business how to better care for ongoing and future eventualities.

In a rapidly warming world, Clarke and Bettini think ahead to the challenge of imagining and practicing care across borders - between bodies, nation states and across the Earth System as a whole. Their concern is that important developments in policy with regard to climateinduced displacement have potentially adverse consequences for the provision of care where it is most needed. They explore climate migration policy as 'disturbingly complicit' with trends in the global care economy through which the most 'able' carers are siphoned away from where they are most needed. Clarke and Bettini highlight some improbable and touching examples that require a reversal of many assumptions about those who give care. Their chapter underscores the need to salvage and nurture, as they put it, some very deep modalities of care, generosity and hospitality that are commonly and routinely extended often by those in need of care themselves - to strangers. This care is not formulaic, it is not 
'policy', it is fraught with tension and impurity, but their suggestion is that it needs affirmation. Hence, Clarke and Bettini suggest that there is an urgent need to bring together the critical analysis of global climate displacement with critical studies of global care chains and they offer some initial ideas about how this might come about.

The modalities of care and attention and the possibilities available for caring are also explored in Schillmeier's chapter. Thinking through two case studies of care-giving in a health care setting in Germany this is a chapter about situated care and the situation of care. The situation, argues Schillmeier, raises questions about the what, how and who is cared for. From these cases Schillmeier details the contours of a cosmopolitics of care in these specific locations. He calls for a sensitivity to shifts in the situation that prompt assumptions about both the directionality and temporality of care. Schillmeier takes us slowly through his two case studies so that we can really feel these shifts. A seeming lack of care, for example, can become care again through concerns and worries that are expressed in language. He shows how painfully easy it is for care to become uncaring, and how difficult it is for something like policy to attend to what he calls the 'worlding souls of caring relations' that are so crucial in providing good care in practice.

\section{Care /policy relations}

A second theme explored within this collection is the way policy-care relations reflect a tension between the commonly assumed features of policy and those of care. The authors cite recent theorising and empirical work that configures care as an inter-relational achievement of people, technologies and concepts and on-going practices of tinkering (Mol, 2008; Mol, Moser, Pols, 2010), hesitation and paying due attention (Stengers, 2011), response-ability (Barad 2007; Schrader 2010) and experimentation (Schillmeier, 2014). This sense of care is in conflict with an understanding of policy as imposing standards and schedules, following protocols, and achieving predetermined outcomes. The authors clustered within this theme show that part of the problem is that some of the ways in which policy is articulated and enacted mask practices that carry care. Their contributions explore both policy and care practices as situated practices. These sets of practices produce ways of knowing and doing reality that sometimes fit together, sometimes rub alongside one 
another, and sometimes collide, conflict and erase one another. Tracing these intrarelationalities is an important intervention as they enact conditions of possibility for future relations of care or harm. Contributions under this theme include research locations where care and policy are held apart by various practices, institutions and materio-semiotic arrangements. Policy has a strong presence in Natalie Gill's contribution but the chapters by Manuel Tironi and Israel Rodriguez-Giralt and Monica Greco, in contrast, explore locations where policy is glaringly absent.

Drawing on an account of a local authority street survey at a waste and recycling department in the North West of England, Gill's chapter is concerned with the role that the practices of European domestic waste policy play in articulating the social contours of place. She shows that the mundane practices of a survey, carried out as part of such policy, have a significant effect on what counts as good care. But also, the care-politics of the street survey are materially constituted, and Gill explores how calculative policy technologies build locations together in ways that are invisible to local residents, complicating a sense of good care and citizenship for those positioned by the survey. She argues that policy practices are performative of realities that shape the possibilities for engagement as citizens. European waste policies differentially enhance common worlds.

The starting point for Tironi and Rodriguez-Giralt's contribution is a community in Chile living in a smelting zone who are seeking environmental justice for the circumstances and suffering that have become normalised and uneventful features of everyday life. Their chapter is an account of ontological invisibility in the public sphere. They note the way in which what is rendered visible and what is cared for converge. In addition, a powerful politics is at play in this community through the rendering of the lives of local community members as sacrificial. The authors seek to understand and to interrogate the political capabilities of locally-organised care-work. They meticulously describe the different ways that care practices, through enduring, and through knowing,offer a resource for the endurance but also the politicization of a community that is suffering extraordinary environmental injustice. At the same time the authors' analysis attends to the ambivalences of the community's 'self-help' practices. For Tironi and Rodriguez-Giralt, care-full policy, if present, could support the community in Chile that is seeking justice. 
The way that a particular milieu shapes forms of legitimacy and authority is also explored in Greco's chapter. The chapter is not focused on any one particular policy, but rather Greco's argument articulates how the features of healthcare systems affect the possibility of engaging in a speculative practice of explanation. Her chapter focuses on Medically Unexplained Symptoms (MUS) as a contested illness and the responses of patients and practitioners in terms of diagnosis and care. Greco argues that the nature of symptoms are impacted by the explanations offered for them. She shows that a mind/body and emotional/physical contrast has long underpinned medical practices. Practitioners themselves acknowledge the limits of these contrasts, aware that the physiological/emotional are interrelated. They also assume patient sensitivities around a psychological explanation and avoid it, even in the face of patients' request for this type of explanation. Greco argues that in place of the above 'contrasts' there are currently emerging another set of contrasts that are primarily concerned with the pragmatics of the explanations. These explanations are co-produced with patients and both patients and doctors are reflexively aware that explanations are productive of the illness itself. This, drawing on work by Isabelle Stengers is explored as a kind of 'speculative pragmatism'. 'Care' is engaged with here through 'practices of explanation' and 'creative accountability'. Greco shows that the practices of diagnosis and care for patients with Medically Unexplained Symptoms is a complex space of problematization that denies the possibility of clear guidelines for practice. This is a space in which institutionalisation and universalisation are not helpful, rather clinical interventions are specific and pragmatic explanations are generative.

\section{Thinking in the tension}

While many of the contributions highlight the various modes of attention in care-policy practices that give visibility to that which is often disarticulated, including hesitation (Schillmeier), vulnerability and openness (Clark and Bettini), at the same time it is acknowledged that these modes of attention are often in tension with policy protocols (Lavau and Bingham, Gill). However, friction can be productive of new ways of caring (Tsing, 2005; Haraway, 1991; Verran, 2001). Some of the authors stay with this friction and ask: How is it possible to promote formal recognition of care practices and to make such practices more visible to policy makers (Singleton and Mee). At the same time, authors are concerned that in the process of increasing visibility those care practices may become 
impoverished, perhaps through certain modes of codification and quantification (Joks and Law). How does/could policy acknowledge situated practices of care in ways that preserve some form of transportability? Many of the authors try to think with the tension between the scales of policy and situated care practices and imagine methods that may hold these scales in tension or allow them to go-on-together in difference. The contributions under this theme are those by Vicky Singleton and Steve Mee, Solveig Joks and John Law, and Jennifer Gabrys. In these chapters the authors explicitly 'care' about policy as they explore how their observations and stories might support, as well as intervene in, policy practices in order that they could care differently.

Singleton and Mee draw on feminist technoscience studies, telling vignettes of clinical care practices in order to unsettle the recent policy imperative for 'compassion at the heart of healthcare' (Department of Health, p 3) and to complexify the relation between policy and located practices of care. Singleton and Mee insist on an appreciation of the specific and situated ways in which care is done, figuring care as a selective, affectively charged mode of attention. Attending to stories is one way in which such attunement can be achieved. These can be difficult, troubled stories which reveal the deeply relational, costly and imperfect work of caring. They may also, however, be a powerful resource for the generation of better caring relations into the future.

Joks and Law look at differences in inherited modes of caring for salmon between Sámi local ecological experts and biological modellers. Their paper shows that caring is historical and rooted in epistemic practices. Such practices are converging around the plight of salmon fishing in Northern Norway. The number of salmon returning and spawning has declined drastically so policies that limit fishing and attempt to control local fishing practices are being imposed. Joks and Law, following Verran (2001), ask how different modes of caring might 'go on well together in difference'. The authors suggest that both scientists and local ecological experts care for salmon, but do so in very different ways. The biologists divide nature from culture to care for salmon populations and, in practice, the population biology does not care for local ecological knowledge or people in ways recognisable to Sámi. By contrast, Sámi modes of caring simultaneously respond to salmon, to the river, and to Sámi economic and cultural practices, but not to population projections. The authors argue that biology and Traditional Ecological Knowledge (TEK) are different ways of knowing and being 
that cannot be collapsed into one another. Rather they suggest experimenting with various practical tools that create material and metaphorical spaces that allow different modes of caring to go on together in difference. Joks and Law are committed to exploring how the present power-saturated intersection between these two ways of caring, knowing and being might be rendered more productive.

Gabrys' chapter connects with that of Joks and Law, and that of Greco, in that she uses the idea of a 'speculative approach'. Gabrys argues that a focus on the speculative dimensions of evidencing harm may allow more consideration of the processual and participatory aspects of establishing how best to care. In the face of new fracking technologies - including their associated infrastructures and possible effects - she suggests that we may need to rethink care not simply as a prescriptive or normative relation, but as a speculative mode of encounter that relies on different collectives that are in-forming themselves through their own emergent monitoring practices. This is a call for a deliberately speculative engagement with citizen-based monitoring, where harm is yet to be understood. Gabrys is interested in trying to articulate a different kind of environmental policy - one that is more responsive to expanded accounts of the experience and evidence of the harm of air pollution, as captured through citizen sensing practices. Air pollution policy, she suggests, could itself become as atmospheric, speculative and responsive as the conditions it would regulate.

The collection is drawn together with a postscript by Richard Freeman that reflects on the contributions from a critical policy studies perspective. Freeman asks what can be learned about how to think care and policy together. Arguing, as we have done here, that policy is a practice in the same way that care is, he notes that many of the case studies feature discrepant policy and care practices. This observation helps us to realise, then, that it may be just as important to see how policies and care are kept apart as it is to highlight their entanglement. This apartness may in fact create room for new sensitivities and relations, as some of our authors suggest. Freeman highlights the ways in which the authors variably explore discrepancies, and how, in practice, the authors show that they might be creatively resolved. Like many of our authors, he is keen to explore sites and public fora that have the potential to bring policy into an 'immediate and meaningful relationship with care'.

\section{References}


Atkinson-Graham, M., Kenney, M., Ladd, K., Murray, C.M., Simmonds, E.A.J., (2015), 'Care in context: Becoming an STS researcher', Social studies of science, 45 (5), pp.738-748.

Ball, S. J., Junemann, C., (2012), Networks, New Governance and Education, Bristol: The Policy Press.

Barad, K., (2003), 'Posthumanist Performativity: Toward an Understanding of How Matter Comes to Matter', Signs: Journal of Women in Culture and Society, 28 (3), pp. 801- 831. Barad, K., (2007), Meeting the universe halfway: Quantum physics and the entanglement of matter and meaning. Durham: Duke University Press.

Caldwell, L. K., (1968), Science, Technology and Public Policy: A Selected and Annotated Bibliography. Bloomington, IN: Indiana University Press.

Cambridge Dictionaries online, (2016)

http://dictionary.cambridge.org/dictionary/english/policy (accessed 4.7.16).

Clarke, J., (2012), The work of governing, in: K. Coulter and W.R. Schumann, (eds), Governing cultures: anthropological perspectives on political labor, power and government, New York: Palgrave, pp. 209-232.

Clarke, J., Newman, J., (2012), 'The alchemy of austerity'. Critical social policy,

32 (3) pp. 299 - 319. Convery, I., Mort, M., Baxter, J., Bailey, C., (2008), Animal disease and human trauma. Basingstoke: Palgrave Macmillan.

Department of Health, (2013), Final Report of the Mid Staffordshire NHS Foundation Trust Public Inquiry, available at: https://www.gov.uk/government/publications/report-of-themid-staffordshire-nhs-foundation-trust-public-inquiry (accessed 7 April 2017).

Easthope, L., Mort, M., (2014), 'Technologies of recovery: plans, practices and entangled politics in disaster', The Sociological Review, 62 (1) pp. 135-158.

Freeman, R., (2009) 'What is 'translation'?', Evidence and policy, 5, pp. 429-447.

Freeman, R. , Sturdy, S., (2014), Knowledge in Policy: embodied, inscribed, enacted. Bristol: Policy Press.

Gilligan, C., (1982), In a different voice. Cambridge, Mass.: Harvard University Press.

Haraway, D., (1991), Simians, Cyborgs and Women: the Reinvention of Nature, London: Free Association Books.

Hargrove, E. C. (1975), The missing link: The study of the implementation of social policy. Available at: http://nonykujun.ru/sohibiv.pdf (accessed 7 April 2017). 
Harrison, S., Mort, M., (1998) , 'Which Champions, Which People? Public and User Involvement in Health Care as a Technology of Legitimation', Social Policy and Administration, 32 (1) pp. 60-70.

Hogwood, B. W., Gunn L. A., (1984), Policy Analysis for the Real World, Oxford:

Oxford University Press.

Hill, M., Varone, F., (2014), The public policy process. London: Routledge.

Hill, M., Hupe, P., (2002), Implementing Public Policy: Governance in Theory and in Practice, London: Sage.

Hudson, B., (2016) The failure of privatised adult social care in England: what is to be done? available at: https://chpi.org.uk/wp/wp-content/uploads/2016/11/CHPI-SocialCare-Oct16Proof01a.pdf (accessed 7 April 2017).

Korpi, W., Ferrarini, T.,Englund, S., (2013), 'Women's Opportunities under Different Family Policy Constellations: Gender, Class, and Inequality Tradeoffs in Western Countries Reexamined', Social Policy, 20 (1)pp. 1-40.

Latimer, J., (2000). Socialising disease: medical categories and inclusion of the aged. The Sociological Review, 48 (3), pp. 383-407.

Latour, B., (2004), 'Why has Critique Run out of Steam? From Matters of Fact to Matters of Concern', Critical Inquiry, 30, 225-248.

Law, J., Singleton, V., (2014), 'ANT, Multiplicity and Policy', Critical Policy Studies, 8 (4) pp. 379-396.

Lendvai, N., Stubbs, P., (2009), 'Assemblages, translation, and intermediaries in south-east Europe: rethinking transnationalism and social policy', European societies, 11 (5) pp. 673695.

Leem, S.Y., (2015), 'The anxious production of beauty: Unruly bodies, surgical anxiety and invisible care', Social studies of science, 46 (1) pp. 34-55.

Lingard, B., Sellar, S., (2013), 'Globalization, edu-business and network governance: the policy sociology of Stephen J. Ball and rethinking education policy analysis', London Review of Education, 11 (3) pp. 265-280.

Martin, A., Myers, N., Viseu, A., (2015), 'The politics of care in technoscience', Social Studies of Science, 45 (5) pp. 625-641.

Matland, R. E., (1995), 'Synthesizing the implementation literature: The ambiguity-conflict model of policy implementation', Journal of public administration research and theory, 5(2) pp. $145-174$. 
May, C., Rapley, T., Moreira, T., Heaven, B., (2006), 'Technogovernance: Evidence, subjectivity, and the clinical encounter in primary care medicine', Social Science and Medicine, 62 (4)pp. 1022-1030.

Milligan, C., Roberts, C., Mort, M., (2011), 'Telecare and older people: who cares where?', Social Science \& Medicine, 72 (3) 347-354.

Mol, A., (1999), 'Ontological politics. A word and some questions', The Sociological Review, 47 (1) pp. 74-89.

Mol, A., (2002), The Body Multiple: Ontology in Medical Practice, Durham, N. Ca., and London: Duke University Press.

Mol, A., (2008), The Logic of Care: Health and the problem of patient choice, London and New York: Taylor and Francis.

Mol, A., Moser, I., Pols, J., (eds), (2010), Care in practice: On tinkering in clinics, homes and farms, Bielefeld:Transcript Verlag.

Moser, I., (2008), 'Making Alzheimer's disease matter. Enacting, interfering and doing politics of nature', Geoforum, 39 (1) pp. 98-110.

Mosse, D., (2005), Cultivating Development: An ethnography of Aid Policy and Practice, London \& New York: Pluto Press.

Murphy, M., (2015), 'Unsettling care: Troubling transnational itineraries of care in feminist health practices', Social studies of science, 45 (5) pp. 717 - 737.

Pols, J., (2006). Accounting and Washing: Good Care in Long-Term Psychiatry. Science, Technology \& Human Values, 31 (4) pp.409-430.

Pols, J., (2012), Care at a Distance: On the Closeness of Technology, Amsterdam: Amsterdam University Press.

Pressman, J.L., Wildavsky, A., (1984), Implementation: How Great Expectations in Washington are dashed in Oakland: or, why it's amazing that federal programs work at all, this being a sagaf the economic development administration as told by two sympathetic observers who seek to build morals on a foundation of ruined hopes. Berkeley: University of California Press.

Puig de la Bellacasa, M., (2011), 'Matters of Care in Technoscience. Assembling Neglected Things', Social Studies of Science, 41(1) pp. 86-106.

Schrader, A., (2015), 'Abyssal intimacies and temporalities of care: How (not) to care about deformed leaf bugs in the aftermath of Chernobyl', Social studies of science, 45(5) pp. : 665690. 
Schillmeier, M., (2014), Eventful Bodies: The Cosmopolitics of Illness, Farnham: Ashgate. Schillmeier, M., Domènech, M., (2010), (Eds.) New Technologies and Emerging Spaces of Care. Farnham: Ashgate

Schrader A., (2010), Responding to Pfiesteria piscicida (the Fish Killer) Phantomatic Ontologies, Indeterminacy, and Responsibility in Toxic Microbiology. Social Studies of Science, 40 (2) pp. 275-306.

Scott, J. C., (1998), Seeing Like a State. New Haven, CT: Yale University Press.

Sevenhuijsen, S., (2003), The place of care: The relevance of the feminist ethic of care for social policy. Feminist theory, 4 (2)pp. 179-197.

Stengers, I., (2011), 'Compasion as a matter of concern', Common Knowledge, 17 (1) pp. 4863.

Spandler, H., Stickley, T., (2011), 'No hope without compassion: the importance of compassion in recovery-focused mental health services', Journal of Mental Health, 20(6) pp. 555-566.

Singleton, V., (2005), 'The promise of public health: vulnerable policy and lazy citizens', Society and space, 23 (5) pp. 771-786.

Singleton, V., (2012), 'When contexts meet: feminism and accountability in UK cattle farming', Science, Technology and Human Values, 37 (4) pp. 404-433.

Suchman, L., (2012),.'"4 Configuration"', Inventive methods: The happening of the social, 48. Ticktin, M.I., (2011), Casualties of care: immigration and the politics of humanitarianism in France, California: Univ of California Press.

Tronto, J. C., (1993), Moral boundaries: A political argument for an ethic of care. Psychology Press.

Tronto, J. C., (2005), 'Care as the Work of Citizens: A Modest Proposal', pp. 130- 145 in

Friedman, M., (Ed.), Women and Citizenship, Oxford: Oxford University Press.

Tsing, A L., (2005), Friction: An ethnography of global connection, Woodstock: Princeton University Press.

Tyler, I., (2013), Revolting subjects: Social abjection and resistance in neoliberal Britain. London, New York: Zed Books.

Verran, H., (2001), Science and an African logic. Chicago: University of Chicago Press. Verran, H., (2002), 'A Postcolonial Moment in Science Studies: Alternative Firing Regimes of Environmental Scientists and Aboriginal Landowners', Social Studies of Science, 32 pp. 729762. 
Viseu, A., (2015), 'Caring for nanotechnology? Being an integrated social scientist', Social studies of science, 45 (5) pp. $642-664$.

Waterton, C., (2002). 'From Field to Fantasy: Classifying Nature, Constructing Europe', Social

Studies of Science, 32(2) pp. 177-204.

Waterton, C., Wynne, B.,(1996), 'Building the European Union: Science and the

Cultural Dimensions of Environmental Policy', Journal of European Public

Policy 3(3) pp. 420-40.

Welsh, I., Wynne, B., (2013), 'Science, Scientism and Imaginaries of

Publics in the UK: Passive Objects, Incipient Threats', Science as Culture, 22 (4)pp. 540-566.

Wynne, B., (2001), 'Expert Discourses of Risk and Ethics on Genetically Manipulated

Organisms: The Weaving of Public Alienation', Politeia, 17(62) pp. 51-76.

Wynne, B., (2002), 'Risk and Environment as Discourses of Technology: Reflexivity Inside

Out?', Current Sociology, 50 (3) pp. 459-477.

\footnotetext{
${ }^{1}$ For example, in his account of the history of the concept of care, Warren T. Reich (1995) claims that a little known Greaco-Roman myth known as "Care" has given shape to ideas of care that we find in later literatures. The Myth of Care describes the struggles between opposing meanings of care - care as solicitude and care as a burden - that many later authors grapple with. Moreover, the Myth of Care entails an understanding of the way in which care is central to what it is to be human. The meaning of care is also rooted in the practical work of the care of souls tradition - a tradition that is principally one of healing those with troubles - be they spiritual, mental or physical. The care of souls tradition produced 3 bodies of literature: practical care based moral reasoning; consolation literature; the art of dying literature. In the 18th and 19th centuries care made an appearance in German literature when Goethe wove the themes of the Myth of Care into his work, Faust. Kierkegaard draws on Goethe and the Myth of Care and is the first philosopher to discuss care. He saw care as central to understanding human life and introduces interest/ concern to an understanding of care, where concern is the impetus for moral action. Heidegger, influenced by Kierkegaard, puts care at the centre of his philosophical thought. But rather than seeing concern as subjective, he uses it to describe the basic structure of the human self. Much of this earlier work on care is Care is then picked up by Rollo May, who pioneered the humanist school of psychology where care becomes the capacity to feel that something matters. It should be noted that the development of the concept of care in these literatures is one rooted in a eurocentric world view.

${ }^{2}$ We do not discuss care as a form of attention that is part of the nature of being (Heidegger).

${ }^{3}$ Matters of care is a development of Latour's (2004) concept of 'matters of concern', which itself was a politically engaged development of his concept of 'matters of fact' attesting to the constructedness of all knowledge claims.
} 